\title{
Mineração de Dados e Publicidade Comportamental: IMPASSES PARA A REGULAÇÃO DO SPAM E DOS NUDGES NA SOCIEDADE BUROCRÁTICA DO CONSUMO DIRIGIDO
}

\author{
Data Mining and BeHAVIORAL AdVertising: \\ IMPASSES FOR THE REGULATION OF SPAM AND NUDGES IN THE \\ BUREAUCRATIC SOCIETY OF TARGETED CONSUMPTION
}

\author{
MATEUS DE OLIVEIRA FORNASIER ${ }^{1}$ \\ NORBERTO MiLTON PAIVA KNEBEL ${ }^{2}$ \\ FERNANDA VIERO DA SILVA ${ }^{3}$
}

RESUMO: Este artigo estuda a necessidade de regulação das estratégias de spam e nudge a partir da crítica da vida cotidiana (Lefebvre), a qual complementa a reflexão sobre a necessidade de proteção tendo em vista a vulnerabilidade do consumidor, situando-se em ponto diverso e independente no debate entre autonomia e paternalismo no Direito do Consumidor, mas também crítico a teses como a do paternalismo libertário. Sua hipótese é de que os nudges são estratégias de incentivo e convencimento disponíveis em alguns aspectos da escolha humana, sendo um campo amplo ligado à psicologia e à economia comportamentais, com uma utilização significativa, no marketing e na publicidade digitais, sendo as técnicas de spam e de nudges usadas por profissionais dessas áreas para influenciar o comportamento do consumidor na sua tomada de decisões, tendo significativas ofensas potenciais aos direitos fundamentais do consumidor, principalmente a privacidade e a autonomia. Como resultado principal, tem-se que a regulação da mineração de dados no âmbito do Direito do Consumidor encontra um profundo impasse: a dogmática jurídica não compreende o papel contraditório e alienante que é o do consumidor e, portanto, não enfrenta o problema da liberdade de escolha e da publicidade com a profundidade necessária - ao nível da linguagem e da ideologia. Frente à inevitabilidade da manipulação de dados na era da big data, sugere-se uma regulação social, tendo como objetivo a auditabilidade social das plataformas que manipulam dados, sendo os usuários capazes de interpretar e

\footnotetext{
${ }^{1}$ Professor do Programa de Pós-graduação Stricto Sensu (Mestrado e Doutorado) em Direito da Universidade Regional do Noroeste do Estado do Rio Grande do Sul (UNIJUí). Doutor em Direito pela Universidade do Vale do Rio dos Sinos (UNISINOS), com Pós-Doutorado em Direito pela University of Westminster (Reino Unido).

${ }^{2}$ Doutorando em Direito pela Universidade Regional do Noroeste do Estado do Rio Grande do Sul (UNIJUÍ).

${ }^{3}$ Bolsista de Iniciação Científica PIBIC/CNPq. Acadêmica do curso de Direito da Universidade Regional do Noroeste do Estado do Rio Grande do Sul (UNIJUí).
} 
analisar os algoritmos que interferem cotidianamente em suas vidas. Metodologia: método de procedimento dialético, com abordagem qualitativa e técnica de pesquisa bibliográfico-documental.

PAlavRas-Chave: publicidade abusiva; spam; nudge; privacidade; consumo.

ABSTRACT: This article studies the need to regulate spam and nudge strategies based on the critique of everyday life (Lefebvre), which complements the reflection on the need for protection in view of the consumer's vulnerability, at a different point and independent in the debate between autonomy and paternalism in Consumer Law but is also critical of theses such as that of libertarian paternalism. Its hypothesis is that nudges are incentive and convincing strategies available in some aspects of human choice, being a broad field linked to behavioral psychology and economics, with significant use in digital marketing and advertising, being spam techniques and nudges used by professionals in these areas to influence consumer behavior in his/her decision-making, having significant potential offenses against fundamental consumer rights, especially privacy and autonomy. As a main result, the regulation of data mining within the scope of Consumer Law finds a profound impasse: legal dogmatics does not understand the contradictory and alienating role that is of the consumer and, therefore, does not face the problem of freedom of choice and advertising with the necessary depth - at the level of language and ideology. Faced with the inevitability of data manipulation in the era of big data, social regulation is suggested, aiming at the social auditability of platforms that manipulate data, with users being able to interpret and analyze the algorithms that interfere daily in their lives. Methodology: dialectical method of procedure, with qualitative approach and bibliographic-documentary research technique.

KEYWORDS: abusive advertising; spam; nudge; privacy; consumption.

\section{INTRODUÇÃO}

A "mineração de dados" (do inglês "data mining") consiste em uma grande gama de práticas que se valem de um conjunto de ferramentas para descoberta de informação e sua consequente transformação em conhecimento. Esse conjunto de técnicas também pode ser chamado de "Descoberta de Conhecimento em Bases de Dados, ou "Knowledge Discovery in Databases" (KDD), e se trata da tentativa de solucionar problemas relacionados ao aumento exponencial da quantidade de dados disponíveis atualmente (CAMILO; SILVA, 2009, p. 3). Entretanto, o tema 
verticaliza-se na especificidade da aplicação da mineração de dados para o uso na publicidade comportamental - principalmente com as técnicas de spam e nudge.

A relação entre a captação de dados e seu uso na publicidade na era informacional tem sido recorrente na literatura jurídica - por exemplo, o Manual de Proteção de Dados Pessoais elaborado pela Escola Nacional de Defesa do Consumidor $(2010)^{4}$, que trata da relação entre informações pessoais e proteção dos dados digitais nas relações de consumo, principalmente quanto à sua regulação. $\mathrm{O}$ texto trata dos temas da Publicidade Comportamental, da formação de perfis (profiling) no campo das redes sociais e da ascensão e necessidade de controle da técnica mercadológica do spam. Com isso, nota-se também a evolução dessa técnica para o campo dos chamados nudges. Assim, o problema que norteou esta pesquisa pode ser expresso no seguinte questionamento: como regular a utilização de dados pessoais para técnicas de incentivo ao consumo?

Como hipótese a tal questionamento, tem-se que os nudges nada mais são que os "empurrões", "gatilhos" ou estratégias de incentivo e convencimento ${ }^{5}$ disponíveis em alguns aspectos da escolha humana. É um campo amplo ligado à psicologia e à economia comportamentais - com uma utilização significativa, assim, no marketing e na publicidade digitais, sendo as técnicas de spam e de nudges usadas por profissionais dessas áreas para influenciar o comportamento do consumidor na sua tomada de decisões, tendo significativas ofensas potenciais aos direitos fundamentais do consumidor, principalmente aqueles atinentes à privacidade e à autonomia. Um exemplo é a utilização de termos como "promoção", ou a oferta de diversos produtos, em que apenas um deles (ou um número pequeno seu) se destaca pela sua oferta a um preço mais atrativo, impulsionando o consumo. Segundo a organização Endeavor, ${ }^{6}$ os empresários devem utilizar essa técnica para angariar consumidores, segundo os seguintes princípios: (I) ter mais opções não significa melhores escolhas; (II) traduzir os benefícios para a linguagem do consumidor; (III) se há dúvidas, o consumidor sempre escolhe a opção padrão; e (IV) não economizar nos incentivos que fazem o consumidor escolher quem promove.

Esse contexto é de estabelecimento de técnicas ligadas ao estudo do comportamento do consumidor, cada vez mais aperfeiçoadas pela quantidade de

\footnotetext{
${ }^{4}$ intitulada "A proteção de dados pessoais nas relações de consumo: para além da informação creditícia"

${ }^{5}$ Conforme a chamada "teoria do $n u d g e$ " são os indicativos de pequenos empurrões em direção a uma decisão, eles podem influenciar no comportamento das pessoas em diversos campos como aponta a matéria da Época Negócios (2018): (1) na hora de pedir comida; (2) na fila do caixa; (3) nas redes sociais; (4) ao pagar plano de previdência; (5) enquanto espera o metrô; (6) ao ler corresondências; (7) ao pesquisar passagem aérea; (8) ao fazer compras online.

${ }^{6}$ Texto "quatro técnicas para influenciar o comportamento do consumidor na sua tomada de decisão", disponível em: https://endeavor.org.br/marketing/4-tecnicas-para-influenciar-ocomportamento-consumidor-na-sua-tomada-de-decisao/.
} 
informações que as empresas de marketing eletrônico possuem dos usuários, sendo no cenário do big data a produção de dados pessoais algo inevitável e com relação direta às relações de consumo, tendo em vista que, mesmo quando os consumidores não estão consumindo, esses comportamentos são úteis aos analistas de dados para descrever e prever o comportamento futuro dos usuários. E mais, na era dos nudges, influenciar os usuários a tomarem decisões consideradas corretas ou racionais segundo os significados do consumo.

O texto tem o objetivo geral de analisar a necessidade de regulação do tema a partir da teoria social de Lefebvre, que é a crítica da vida cotidiana, principalmente a partir do descrição da sociedade pelo termo "sociedade burocrática de consumo dirigido", expondo a condição do sujeito sob o capitalismo. Em outros termos: trata de como ser consumidor de modo notadamente irracional, transformado em objeto. Essa teoria busca complementar a reflexão sobre a necessidade ou não de proteção tendo em vista a vulnerabilidade do consumidor, situando-se em ponto diverso e independente no debate entre autonomia e paternalismo no Direito do Consumidor, mas também crítico a teses como a do paternalismo libertário.

Para isso, metodologicamente a pesquisa se valeu do método de procedimento dialético, com abordagem qualitativa e técnica de pesquisa bibliográfica e documental. Primeiramente, o texto trata da mineração de dados como tecnologia e sua aplicação na publicidade comercial, do spam aos nudges, traçando estratégias jurídicas do Brasil para a regulação. Já a sua segunda parte traz uma reflexão teórica crítica sobre a ideologia do consumo e o impasse da regulação estatal frente ao fenômeno profundo que é o consumo baseado na satisfação.

\section{MiNERAÇÃO DE DADOS: DO SPAM (PERTURBAÇÃO) AOS NUDGES (INDUÇÕES) NA ERA DA BIG DATA}

O data mining é um processo definido pela descoberta, sejam por meios manuais ou automatizados. É útil para a análise exploratória de questões sem noções predeterminadas - então, a mineração de dados é a busca pela novo, valorável e não trivial em grandes volumes de dados. Também é um esforço cooperativo entre humanos e máquinas, na prática, tendo os dois objetos primários: (I) predição, que envolve o uso de variáveis e campos para prever valores desconhecidos e futuros em interesses variados; e (II) descrição, que foca em procurar padrões para descrever os dados de formas interpretáveis por humanos (KANTARDZIC, 2020, p. 2-3). A mineração de dados é motor da chamada economia digital, ou da mercantilização dos dados, em que os dados pessoais se transformam em mercadoria. Consolida-se, conforme Ciuriak (2018), uma economia orientada por dados como um modelo novo de negócios formado por: (I) assimetria informacional entre usuários e controladores de dados; (II) a industrialização do aprendizado nas inteligências artificiais; (III) economia monopolista, proliferandose as chamadas big techs; (IV) novas formas de transação de ações; e (V) riscos sistêmicos devido às vulnerabilidades das infraestruturas de proteção de dados. 
A valorização da mercadoria constituída pelos dados pessoais depende, portanto, de um sistema diretamente ligado a uma infraestrutura de gestão e análise da informação - pois, no big data, a possibilidade técnica de extração e de transformação em mercadoria (commodification) é o que faz com que os dados pessoais e metadados comportamentais dos consumidores se convertam em ativos na economia da informação (BIONI, 2019, p. 39). Os dados em si não possuem valor mercantil relevante antes da sua operacionalização nos sistemas de informação, consistentes na rendição do usuário, que entrega seus dados para poder usar os serviços digitais, para as empresas que transformam suas experiências da vida real, do seu cotidiano, em dados rentáveis - ou seja, é uma rendição do corpo, dos hábitos, da vida cotidiana para a manipulação lucrativa de quem consegue operar esses dados no mercado, sob a promessa de uma personalização dos resultados de buscas e dos serviços (ZUBOFF, 2019, p. 222). Os bancos de dados, antes utilizados somente para armazenar específicos dados de crédito, hoje são utilizados em "promiscuidade" (BIONI, 2019, p. 61), armazenando e organizando dados comportamentais, os comprando e os vendendo.

As técnicas de mineração de dados utilizadas para prever e descrever comportamentos na mineração de dados, tornando-os rentáveis, podem ser assim elencados (KANTARDZIC, 2020, p. 3): (I) classificação (classification): descoberta de uma função preditiva que classifica dados em classes pré-definidas; (II) regressão (regression): função preditiva que mapeia dados para um valor variável; (III) agrupamento (clustering): função descritiva que identifica uma série de categorias ou clusters para descrever dados; (IV) sumarização (summarization): função descritiva que envolve métodos para encontrar uma série de dados; $(\mathrm{V})$ modelagem de dependências (dependency modeling): função descritiva que busca dependências entre variáveis e valores; e (VI) detecção de variáveis e desvios (change and deviation detection): descoberta de mudanças significativas nas séries de dados.

Uma das aplicações dessas técnicas é a do spam publicitário, ${ }^{7}$ que consiste no envio de e-mails indesejados de acordo com os interesses registrados pelo usuário em sua navegação pelo comércio eletrônico - e essa prática pode ser feita também por comércio legítimo, que se utiliza de técnicas questionáveis ou, até mesmo, fraudes propriamente ditas. ${ }^{8}$ Essa técnica representa a capacidade da tecnologia da informação explorar (no sentido de expropriar) os pontos que agregam a atenção humana, sendo os spammers responsáveis por encontrar locais para prender a atenção das pessoas, fazendo com que desperdicem seu tempo em nome do próprio benefício dos fornecedores/anunciantes (BRUNTON, 2013, p. 200-203). Esse

\footnotetext{
7 A história dessa técnica de publicidade é exposta por Ferrara (2019) desde as cartas físicas indesejadas no final do século XIX até os spams controlados por inteligência artificial da atualidade.

${ }^{8}$ O livro de Krebs (2014) descreve o fenômeno global da utilização dos dados pessoais para realização de cibercrimes por meio de spam, forjando fraudes baseadas em malwares, spywares, bots, ransomware, entre outros.
} 
sistema produz grupos de interesse forjados com a ajuda de máquinas, com o objetivo de soar coerentes aos olhos humanos.

Dessa forma, o correio eletrônico não desejado não pode ser entendido como mera perturbação, pois decorre de uma estrutura complexa baseada na análise dos dados pessoais dos usuários. Aqui se trata da utilização comercial e publicitária dessa técnica, portanto, a "monitoração eletrônica do estilo de vida" (MATOS, 2005, p. 20) das pessoas em nome da realização comercial, sendo uma forma abusiva do uso de mensagem eletrônica (FINKELSTEIN, 2004, p. 148). Nessas práticas, os spammers são empresas de marketing eletrônico que atuam na internet explorando ou até mesmo comprando bancos de dados formados pela captação de informações de usuários dos mais diversos serviços digitais (TEIXEIRA, 2015).

A regulação do spam não pode decorrer de uma observação do fenômeno de forma separada, pois essa técnica só é possível sob uma estrutura de mineração de dados, ou seja, esses dados precisam ter sido coletados de alguma maneira, sendo necessário expor as formas de tratamento desses dados (LEMOS et al., 2007, p. 7). As funções preditivas da mineração de dados implicam conflitos com direitos da personalidade, transformando o direito à privacidade (negativo, de não intervenção no núcleo da vida privada) também na consolidação de um sistema de proteção de dados (COLOMBO; FACCHINI, 2017, p. 69; DONEDA, 2006), tendo em vista a ubiquidade da produção de dados e a massividade do ecossistema digital - ou seja, ocorre uma violação constante à privacidade dos dados pessoais, e os usuários dos sistemas são produtores massivos de dados.

Quanto às políticas públicas de proteção ao consumidor no Brasil, em nível legislativo, algumas considerações devem ser feitas. A Lei 12.965/2014 (BRASIL, 2014), "Marco Civil da Internet", proíbe a guarda de registros de acessos dos usuários pelos provedores de conexão de internet (art. 14) e regula essa guarda na forma sigilosa, consentida, sem fugir da finalidade e em ambiente controlado e seguro nos provedores de aplicações de internet (art. 15 e 16) ${ }^{9}$. Essa lei também aponta para o diálogo entre proteção do consumidor e proteção dos dados, um reconhecimento do papel do consumo eletrônico e necessidade de novas formas de proteção do direito básico do consumidor à proteção de dados pessoais na internet (MENDES, 2016). E, diante disso, a necessidade do reconhecimento da vulnerabilidade do consumidor e sua assimetria informacional também nas relações de gestão de dados, ou seja, reconhecendo-as sob o regime consumerista (SILVEIRA; PERES, 2019).

Já a Lei 13.709/2018, Lei Geral de Proteção de Dados Pessoais (LGPD) (BRASIL, 2018), disciplina a proteção de dados pessoais, promovendo princípios relativos à

\footnotetext{
${ }^{9} \mathrm{O}$ conceito de "provedor" utilizado no Marco Civil da Internet diferencia os (a) provedores de conexão à internet - pessoa jurídica fornecedora do serviço de acesso à rede para os usuários, como as operadoras de banda larga ou operadoras de telefonia (serviços 3G ou $4 \mathrm{G}$ ); e os (b) provedores de aplicação de internet - são a pessoa jurídica que executa algum serviço ou fornece informação conectada na internet, para fins econômicos ou não. (CEROY, 2014).
} 
privacidade e autodeterminação informativa; todavia, também busca conferir estabilidade e segurança jurídica para o comércio de dados - introduzindo a figura do controlador como a quem compete as decisões referentes ao tratamento de dados pessoais, ou seja, o proprietário dos dados pessoais (art. 5, VI) - e também da transferência internacional de dados (art. 33). O sistema jurídico de proteção de dados do Brasil, principalmente com o advento da LGPD busca, além da consolidação de uma "cidadania digital" (MENDES; DONEDA, 2017), a realização do Direito do Consumidor (MIRAGEM, 2019). No caso das técnicas que se utilizam da mineração de dados para enquadrar o comportamento dos consumidores, preocupa-se principalmente com dois direitos básicos do consumidor (art. $6^{\circ}$, CDC): "II - a educação e divulgação sobre o consumo adequado dos produtos e serviços, asseguradas a liberdade de escolha e a igualdade nas contratações;" e "IV - a proteção contra a publicidade enganosa e abusiva, métodos comerciais coercitivos ou desleais, bem como contra práticas e cláusulas abusivas ou impostas no fornecimento de produtos e serviços".

A liberdade de escolha é posta em questão quando cada vez mais a inteligência artificial vigia os consumidores e influencia profundamente as decisões dos consumidores utilizando técnicas de publicidade como os nudges. A igualdade nas contratações e o consentimento, no cenário da big data, são uma contradição frente a profunda assimetria informacional na qual a gestão de dados é profundamente desigual tendo em vista que a administração e interpretação dos dados digitais massivos são feitas pelas corporações informacionais (as big techs), estando do lado oposto dessa relação o consumidor/usuário, desprovido de qualquer dessas habilidades ou infraestrutura (CUKIER; MAYER-SCHOENBERGER, 2013, p. 30). E até mesmo por isso a mercadoria resultante da exploração dos dados é tão valiosa para a economia digital (CRAIN, 2018, p. 90-91), pois decorre da intervenção de complexas infraestruturas, restando ao usuário ser somente objeto de extração.

A proteção contra a publicidade abusiva ${ }^{10}$ ou enganosa ${ }^{11}$ contempla os acessos da publicidade para além da informação ao consumidor. A publicidade comportamental representa esse novo momento das abordagens que tem por objeto a ampla utilização de dados pessoais, significando um aprofundamento da assimetria informacional nas relações de consumo, e relativizando a ideia de livre escolha (ESCOLA NACIONAL DE DEFESA DO CONSUMIDOR, 2010, p. 62). A ascensão de novas formas e tecnologias de publicidade comportamental tem

${ }^{10}$ Art. 37 do CDC: " $\$ 2{ }^{\circ}$ É abusiva, dentre outras, a publicidade discriminatória de qualquer natureza, a que incite à violência, explore o medo ou a superstição, se aproveite da deficiência de julgamento e experiência da criança, desrespeite valores ambientais, ou que seja capaz de induzir o consumidor a se comportar de forma prejudicial ou perigosa à sua saúde ou segurança."

${ }^{11}$ Art. 37 do CDC: §1ำ É enganosa qualquer modalidade de informação ou comunicação de caráter publicitário, inteira ou parcialmente falsa, ou, por qualquer outro modo, mesmo por omissão, capaz de induzir em erro o consumidor a respeito da natureza, características, qualidade, quantidade, propriedades, origem, preço, e quaisquer outros dados sobre produtos e serviços" 
caminhado no sentido contrário ao da livre escolha do consumidor - na direção de um novo "assédio de consumo", cada vez mais ubíquo e subliminar, comprometendo a capacidade de decisão autêntica (VERBICARO; RODRIGUES; ATAÍDE, 2018). A manipulação das emoções, a moldura de insatisfações pessoais e sociais e a criação de satisfações efêmeras sustenta a vulnerabilidade comportamental do consumidor - na qual a indústria publicitária possui a tecnologia e o poder de processar dados massivos e em tempo real de acordo com o comportamento dos usuários, que fica relegado ao consentimento e uma liberdade artificial de escolha (VERBICARO; CRUZ, 2018).

O assédio de consumo consiste em práticas de aliciem e seduzam por meio da repetição o vulnerável consumidor e até mesmo aqueles de vulnerabilidade extremada - como os idosos, crianças, analfabetos e doentes. Podem se dar mediante práticas violentas de publicidade ostensiva, como nas práticas de encantamento e (des) orientação do consumidor (CATALAN; PITOL, 2017, p. 146148). Essa situação se agrava no contexto da manipulação de dados digitais, tendo em vista que a ciência de dados proporciona mais capacidade para a publicidade atuar no campo do comportamento por meio das informações obtidas dos usuários, direta ou indiretamente. Mais que o marketing dirigido a usuários específicos, a publicidade comportamental evoluiu, conforme a massificação da análise de dados digitais, para um patamar de conhecer e influenciar comportamentos de forma profunda.

Enquanto se disciplina a conciliação entre a proteção de dados pessoais e a mineração dos dados como mantenedores das aplicações de internet (TATEOKI, 2017, p. 73), essas plataformas se aperfeiçoam em explorar cada vez mais dados e descrevem, preveem e induzem cada vez mais comportamentos consumistas. A publicidade comportamental e a utilização do perfil consumidor, constantemente atualizado, se valem de práticas que fogem ao consentimento do usuário e interferem em princípios jurídicos já consagrados, embora não tenham regulação específica - como a intimidade e a vida privada, a privacidade, a proteção dos dados digitais (ALVES, 2016, p. 220). A assimetria de infraestrutura para análise dos dados expõe o aumento da vulnerabilidade já reconhecida do consumidor nas relações comerciais. Mecanismos como a formação de perfis de comportamento pela publicidade representam ameaças profundas à igualdade, à privacidade, à personalidade e à proteção de dados pessoais (MACHADO; RUARO, 2017, p. 438). A publicidade comportamental se encontra num rol mais amplo, das publicidades direcionadas, a "tônica dos modelos de negócios na internet" (BIONI, 2019, p. 41), que interpretam a navegação dos usuários, a localização geográfica e as emoções, o que só se torna possível mediante o uso de sistemas de informação que mineram dados em tempo real, sendo, por isso, uma produção de conhecimento mercantil com base em informações pessoais.

O nudge utilizado na publicidade comportamental é prática derivada do cenário de criação de perfis (profiling) - da publicidade na era da big data, tendo em vista o 
aprendizado de máquinas que permite a interpretação desses dados massivos por meio de complexas correlações em tempo real. Camurça (2020, p. 112-115) identifica essa prática pela utilização das técnicas de (I) cookies - arquivo que armazena os registros de comportamento do usuário, como o histórico de acesso a web, os carrinhos de compra e os logins; (II) web beacons - é uma técnica analítica que registra o acesso de usuários por meio de tags ou marcas, diferente dos cookies pois não depende do usuário decidir armazena-los ou não; (III) supercookies - cookies mais resistentes ao ato de exclusão feito pelo usuário, pois não possuem data de validade para deixar de manter registros, todavia, funcionam de forma temporária e breve; (IV) HTML5 web storage - a evolução os arquivos de armazenamento, permitindo mais dados e de melhor qualidade; e (V) fingerprinting - técnica capaz de rastrear os hábitos dos usuários mesmo após a exclusão das ferramentas de armazenagem de seus hábitos na internet por meio de deduções feitas a partir do próprio sistema ou dos dados de outros usuários.

A formação de perfis comportamentais e os envios de mensagens não requeridas como spam representam técnicas descritivas e preditivas da mineração de dados; entretanto, atualmente, na expansão causada pela big data e as inteligências artificias com algoritmos automatizados, há uma ampliação desse processo em direção à indução do consumidor, baseada na imensidão de dados fornecidos incessantemente por este na rede - surgem, assim, técnicas sutis de incentivo ao seu comportamento em determinadas direções, chamadas de nudges. A definição de nudge é um aspecto da arquitetura de escolha que altera o comportamento das pessoas, indicando uma decisão, sem proibir outras opções ou alterar significativamente os incentivos para tomá-la. Esse aspecto é descrito e forjado por um "arquiteto de escolhas" que teria o interesse em promover melhor vida para os outros em cenários amigáveis aos usuários, essas arquiteturas para a escolha podem ser extremamente visíveis e exuberantes, como também podem ser discretas e necessitem profunda atenção (THALER; SUNSTEIN, 2008, p. 8-11). Sunstein (2016) reconhece a possibilidade de nudges manipuladores que devem sofrer objeção ética, pois é necessário manter a integridade da "arquitetura de escolha" - a capacidade da pessoa de tomar decisão baseada nas suas necessidades.

O tipo mais popular de nudge é o da "opção padrão", ou "default options", que é a tendência dos consumidores em assumirem comportamentos conservadores e adquirirem o produto/serviço padrão - de acordo com sua disponibilidade e acessibilidade -, pré-definido, se não houver sugestão contrária (AMBROSINO; FARALLA; MARCO, 2017, p. 3). Também, uma das práticas bastante associadas ao nudge é da opção negativa ou negative option marketing (NOM), que consiste nas práticas de renovação automática de serviços, como os de mídias digitais (Netflix, Spotify, YouTube Premium, etc.), que oferecem períodos de teste ao usuário, gratuitos, mas que, sem a realização da opção contratual negativa explícita da parte do consumidor, o serviço passará a ser cobrado, compreendendo uma relação comportamental dos consumidores com a continuidade dos serviços já 
estabelecidos, compreendo o cancelamento como um retrocesso em seus hábitos de consumo (VONBERGEN et al., 2016, p. 157).

\section{Regulação da Mineração de Dados Publicitária NA Sociedade BUROCRÁTICA DE CONSUMO DIRIGIDO}

O nudge nada mais é do que um empurrão, forjado nas teorias da economia e da publicidade comportamental. O fundamento ideológico que sustenta sua aplicação universal está em Thaler e Sustein (2008), que o chamam de"paternalismo libertário". É baseado na economia comportamental e sustenta a supremacia da escolha racional dos indivíduos, dando aos nudges o papel de aprimorar a arquitetura de escolha para indicar melhores decisões em prol da saúde, riqueza e felicidade. Assim, o feedback constante em forma de dados representa a comunicação entre os consumidores e seus fornecedores, permitindo, no futuro, escolhas mais eficientes. A arquitetura de escolhas pode ser baseada em incentivos que fomentem a tomada de decisões, pelas pessoas, que promovam desenvolvimento de suas vidas e dos produtos.

Essa técnica pode se aplicar, entre outros, como política pública ao caso da melhoria da Administração Pública, orientando cidadãos a decisões otimizadas (SOUZA; RAMOS; PERDIGÃO, 2018), da fiscalização tributária, induzindo o cidadão aos benefícios do pagamento de dívidas públicas (FEITOSA, 2019), na saúde pública, ao incentivar doação de órgãos (CIOATTO; PINHEIRO, 2018), ou no campo do consumo, em caso de normas descritivas de produtos, que podem incentivar o consumo de produtos orgânicos ou mais saudáveis (GRODERS, 2017). Trata-se de um cenário que envolve a institucionalização dos nudges e, formalmente, se orienta por princípios de liberdade e transparência (SUNSTEIN, 2017b); todavia, o tema deste é a apropriação privada desses mecanismos, o que pode não seguir princípios públicos, na prática. Essa aplicação privada no campo do consumo é a da publicidade.

Questiona-se, sob a ideologia do consumo capitalista, se é possível tomar decisões racionais frente à profunda irracionalização do consumo - alienado profundamente das necessidades humanas. A crítica da vida cotidiana em Henri Lefebvre (1991, p. 89) compreende o termo "sociedade burocrática de consumo dirigido" para descrever a sociedade capitalista desde a industrialização. Ou seja, é uma análise que entende a mecânica dos movimentos do modo de produção como o motor da cotidianidade. A burocratização sinaliza para a racionalidade da sociedade industrial e o consumo como o objeto de planificação social na forma dirigida. O fim, ou o objetivo dessa sociedade é a satisfação - que se estabelece no saciar momentâneo de um vazio coloca no lugar das necessidades, multiplicandoa e tornando-a repetitiva. Essas (alienadas) necessidades oscilam entre a satisfação e a insatisfação, justamente porque o consumo é organizado de acordo com a satisfação que proporciona. 
O mal-estar nessa sociedade é caracterizado pelo constante desaparecimento desse sentimento de satisfação, retornando ao vazio e reorientando-se pelos significantes de uma nova satisfação. Por meio da cultura, esse mal-estar é inerente a essa sociedade, e constitui um fato social. Os objetos da sociedade capitalista passam por um constante processo que Lefebvre (1991, p. 91) chama de obsolescência da necessidade, que concilia tanto a efemeridade das coisas como coisas, quanto os seus significantes de satisfação - não só os objetos se estragam, mas também a expressão social do desejo neles contida é destruída, e as necessidades envelhecem. Esse processo está diretamente ligado à mobilidade da vida, na qual os objetos, a moradia, as cidades e o "habitar" são constantemente deslocados. Nesse cenário, implicam-se e misturam-se constantemente a procura obstinada por satisfação e o estado de mal-estar da insatisfação.

A realidade da sociedade burocrática de consumo dirigido põe em xeque a sua pretensão racional, da técnica e da ciência. Os valores de finalidade são supostamente colocados em primeiro plano, organizando as forças produtivas para supri-las - estruturando, planificando e programando, numa relação entre ciência e máquinas. Entretanto, por trás de toda essa especialidade dotada de prestígio ilimitado, está uma profunda irracionalização, que aliena as pessoas de suas necessidades, forjando satisfações, expondo os limites da racionalidade do economicismo e do tecnicismo. O consumo torna-se espetáculo em autorreferência por essa dialética entre satisfação e insatisfação, separando os sujeitos das suas reais necessidades:

Daí decorre a autodestruição do objeto e do objetivo: a cidade pitoresca, a região turística; o museu desaparecem sob o afluxo dos consumidores, que acabam consumindo apenas a sua própria presença e sua própria acumulação (LEFEBVRE, 1991, p. 95).

Há uma desmobilização na esfera política das camadas trabalhadoras, tendo em vista o controle ideológico exercido pela indústria cultural, como um efetivo poder político. Trata-se da desconfiguração da individualidade e da verdadeira autonomia (VERBICARO; VERBICARO, 2017, p. 116). A escolha na esfera do consumo é mera formalidade frente ao cenário de massificação e alienação das necessidades, e assim a busca por satisfação nada tem a ver com liberdade de escolha, passando a publicidade a ser o principal o motor dessa história. O consumo interfere diretamente no imaginário social, o qual é fundamentalmente diferente do imaginário individual, pois tem mais a ver com a prática do que com a internalização e a abstração. A publicidade não implica somente na apresentação de uma ideologia do consumo - aquela na qual o "eu" se realiza no consumo mas também, na existência imaginária das coisas, impondo uma retórica e poética 
inerentes às representações: ${ }^{12}$ "o ato de consumir é um ato imaginário (portanto, fictício) tanto quanto um ato real (sendo o próprio 'real' dividido em pressões e apropriações). Ele adquire um aspecto metafórico [...] e metonímico" (LEFEBVRE, 1991, p. 100).

O problema relacionado a isso é que o consumo se apresenta como ato pleno, sem ilusão, ligado às necessidades da vida. A classe trabalhadora vive no meio desses signos do consumo em massa, expondo a publicidade comercial como fenômeno de linguagem que exige atenção pois exerce o papel de "encobrir, dissimular, transpor o real, ou seja, as relações de produção" ${ }^{13}$ (LEFEBVRE, 1991, p. 107). A alienação das necessidades e do valor de uso promovida pelo consumo dos signos serve a repensar a dicotomia liberdade/ paternalismo tão candente ao Direito do Consumidor, tal qual se propôs o "paternalismo libertário", mas revela uma cisão do consumo com quaisquer decisões racionais. Ao mesmo tempo que evidencia a vulnerabilidade do consumidor e considera impossível a concretização de uma liberdade no âmbito do consumo, considera que o paternalismo estatal também não encontra o real problema, pois busca mediar uma relação que é baseada em signos forjados. O grande problema , portanto, é o de ser o consumo a esfera de realização das necessidades humanas. Nesse sentido, a mineração de dados é mais uma fase da tecnologia da publicidade e sua linguagem, capaz de criar signos e forjar expropriações no contexto da massificação dos dados digitais.

O sistema de extração de dados pessoais é, na definição de Zuboff (2019), a realidade do capitalismo contemporâneo - um capitalismo de vigilância (surveillance capitalism) - , no qual a vigilância não tem mais uma função coercitiva, mas sim, de transformação lucrativa das experiências pessoais em dados comercializáveis ${ }^{14}$ - para torná-los utilizáveis de diversas formas, inclusive para a formação de nudges que interessem a setores comerciais específicos, que paguem mais. Há a extração de mais-valia comportamental, ou seja, a vigilância da vida dos usuários ocorre de forma consentida, mas dela é produzida um valor que jamais

\footnotetext{
12 Também, conforme Baudrillard (2000, p. 293): “nem o discurso retórico, nem mesmo o discurso informativo acerca das virtudes do produto tem efeito decisivo sobre o comprado. O indivíduo é sensível à temática latente de proteção e de gratificação, ao cuidado que "se" tem de solicitá-lo e persuadi-lo, ao signo, ilegível à consciência, de em alguma parte existir uma instância [...] que aceita informá-lo sobre seus próprios desejos., adverti-los e racionalizá-los a seus próprios olhos. Ele não acredita na publicidade mais do que a criança no papai noel. O que não impede de aderir da mesma maneira a uma situação infantil inferiorizada e de se comportar de acordo com ela. Daí a eficácia bem real da publicidade, segundo uma lógica que, embora sem ser a do condicionamento-reflexo, não é menos rigorosa: lógica da crença e da regressão."

${ }^{13}$ Nesse sentido também que Bauman (2010, p. 28) compreende a transformação da sociedade de uma sociedade de produtores para uma sociedade de consumidores, alienada de sua importância no campo do trabalho.

${ }^{14}$ Constitui-se o que Vieira e Evangelista (2015) chamam de "máquina de exploração mercantil da privacidade".
} 
retorna ao usuário. ${ }^{15} \mathrm{~A}$ vigilância dos consumidores é algo sólido na economia política do capitalismo, se utilizando de toda e qualquer informação privada para formação dos perfis de interesse dos consumidores (FUCHS, 2011).

A proteção de dados possui um marco regulatório global na esfera dos Direitos Humanos (PINHEIRO, 2020, p. 7) com a previsão da privacidade na Declaração Universal dos Direitos Humanos. Entretanto, para além da afirmação dessa nas ordens jurídicas estatais, registra-se a necessidade de implantação de programas transnacionais que advogam pela proteção dos dados, insurgindo questões como a responsabilidade social empresarial (FORNASIER; FERREIRA, 2015, p. 409) devido à magnitude e importância das empresas transnacionais de tecnologia e sua normatividade interna aplicada globalmente. No Brasil, compreende-se que iniciativas como a LGPD, para além de sua normatividade, podem fomentar uma cultura corporativa de proteção de dados, incluindo compliances de práticas adequadas e relações comerciais com esses princípios (BIONI, 2019, p. 32-33).

As próprias técnicas da psicologia comportamental podem servir a esses princípios, orientando a prática dos nudges noutro sentido, contrário à sociedade de consumo e ao superendividamento ${ }^{16}$, proporcionando práticas de educação do consumidor e desenvolvimento sustentável (VIEIRA; KACHUBA; LOCATELLI, 2020). Também, métodos de análise econômico-comportamental podem servir ao estudo do Direito para promoção de melhores proteções aos consumidores, tendo em vista a investigação dos motivos e comportamentos que apontam para práticas nocivas para cidadãos ou a coletividade, como o endividamento das famílias e o consumo insustentável ou prejudicial à saúde (DAURA, 2018). Para isso, há um desafio relevante de incorporar valores de direitos humanos nesses agentes nãoestatais, um passo além da capacidade estatal de incorporá-los - que visa a manutenção da autonomia pessoal frente ao governo (SUNSTEIN, 2014, p. 47) ${ }^{17}$ quando os nudges publicitários, para bem ou mal, necessitam da massificação da mineração de dados pessoais por controladores privados.

O cenário de responsabilidade social ampliada, do Estado às grandes empresas da economia digital, implica a abertura dos obrigados a orientar a educação e o

\footnotetext{
${ }^{15}$ Conforme Estrada (p. 94): “Todas as pessoas trabalham de graça para as empresas de tecnologia carregando os seus dados pessoais na nuvem, ganhando bilhões de dólares por ano, e estas assemelham-se às empresas petrolíferas, pois a invasão da privacidade e da intimidade das pessoas tornou-se no novo petróleo do mundo, mas o pior de tudo é que só elas que ganham dinheiro, já o resto não ganha um só tostão."

${ }^{16}$ Realidade apontada por Marques (2012 e 2016) como um desafio a proteção do consumidor estruturalmente afetado por dívidas relativas ao consumo, de caráter praticamente impagável tendo em vista a renda - caracterizando um acesso predatório ao crédito.

17 O paternalismo libertário (SUNSTEIN; REISCH, 2019, p. 137-138) propõe uma regulação constituinte sobre a ética dos nudges, ao ponto de serem confiáveis pela população, ou seja, como elemento público e relativo à administração pública, não associado à responsabilidade social das empresas.
} 
consumo inteligente - incentivando práticas ligados ao consumo menos predatório do trabalho e do meio ambiente, em nome de uma nova cultura de consumo na qual as novas tecnologias sejam democraticamente utilizadas para a sustentabilidade ambiental e redução das desigualdades (DOWNBOR. 2007, p. 28). Gajitos (2006, p. 46) fala da orientação para um "consumo sadio", tendo em vista sua realidade doente - a forma consumista. A influência de técnicas que afetam a consciência do consumidor acentua sua vulnerabilidade, e exige um direito à educação para o consumo como processo permanente de incentivo à boas práticas - para além da consciência dos seus direitos como consumidor - e a necessária educação que informa os direitos e orienta a não contratação de serviços e produtos de fornecedores que violam a lei dos consumidores (SERRANO; MARTINEZ, 2020). Mas também revela a necessidade do desenvolvimento de um senso crítico sobre o ato de consumir (BEZEN; NETO, 2020, p. 554) e o papel inerentemente crítico da cidadania (TIUJO, 2018).

A defesa do uso dos nudges sustenta a capacidade do governo estatal em adotar empurrões favoráveis à população. Todavia, a dominação privada das tecnologias sugere outra realidade para essa prática no âmbito consumerista. Por isso, é necessária a intervenção social nessas práticas. E para isso, resta a regulação por meio da auditabilidade social, criando uma cultura de profunda transparência dos algoritmos, para além da formalidade, mas sustentando práticas educativas e informativas que forjam uma audiência pública verdadeiramente crítica dessas práticas, capaz, tecnicamente, de intervenção. É preciso se afastar da noção de consentimento passivo e da mera autorização dos usuários (KEMPER; KOLKMAN, 2018, p. 2092-2093). É necessário também criar mecanismos públicos de esclarecimento aos usuários, para além dos termos de serviço, de forma clara e com linguagem acessível (VEDDER; NAUDSTS, 2017, p. 214), sendo essa uma concepção que entende que não há como a busca por algoritmos justos partirem da Lei ou do Direito estatal, mas de algoritmos com fundamentos abertos e verificáveis (COURTLAND, 2018).

A proeminência de cada vez mais algoritmos que intervêm na vida cotidiana suscita a necessidade de controle social dos mesmos e da apreensão de princípios de proteção do consumidor no âmbito da engenharia dos sistemas. O "Direito como metatecnologia" do qual propõe Magrani (2019, p. 247) se adequa ao contexto de aplicação do Direito no mundo tecnorregulado, no qual as plataformas digitais são administradas globalmente, exigindo a impressão de princípios jurídicos democraticamente estabelecidos, como os Direitos Humanos, no âmago dos códigos, ou seja, em seu desenvolvimento. Portanto, a regulação das práticas algorítmicas não reivindica a dura aplicação da lei, mas está ligada à integração de valores éticos importantes, já contidos no Direito, no design das aplicações orientado-as a educar os usuários e a incentivar cada vez mais formas de participação e auditabilidade social de suas práticas. 
No cenário de cada vez maior mineração de dados, a prática de nudges contempla a realidade assimétrica entre tecnologia e sociedade, na qual os operadores das grandes tecnologias possuem inteligências artificiais que a capacitam de interpretar dados acima de qualquer organização humana. Por isso, a regulação dessas práticas precisa contemplar princípios democráticos na raiz do desenvolvimento, como apontam Lembcke et al. (2019): (I) preservação da liberdade de expressão; (II) ser facilmente identificado como um nudge; e (III) contemplar os objetivos dos usuários. Sunstein (2017a) aponta que o respeito a esses princípios promover uma vida mais simples e permite decisões racionais; todavia, atualmente, as práticas de coleta, gestão e processamento de dados pessoais, altamente concentrada em grandes empresas privadas de tecnologia, suscita a necessidade de regulação ampliada e cooperativa - as empresas precisam conceber princípios de respeito à privacidade, democracia e consciência ambiental no âmbito do desenvolvimento técnico - caso contrário, resta a falta de efetividade na aplicação do Direito estatal frente à realidade globalizada, massiva e impossível de apreender a partir da ciência de dados.

\section{CONCLUSÃO}

O legado do pensamento de Lefebvre sobre a sociedade burocrática de consumo dirigido importa ao dizer como as bases sociais da livre escolha do consumidor são frágeis, tendo em vista a profunda irracionalidade desse consumo baseado em satisfações efêmeras que nada tem a ver com as necessidades. A natureza despolitizadora do consumismo forja um cidadão que não é crítico dos sistemas de produção e consumo, afastado do fundamento de suas consequências - embora acabe sofrendo todas elas - vivendo sob símbolos construídos de satisfação pessoal que o coloca sob assimetria informacional em relação às grandes empresas de tecnologia - ou seja, o sujeito consumidor acaba orientado a um comportamento burocrático de consumo creditado falseamento à suas próprias escolhas. A prática do nudge fundada no paternalismo libertário sofre aqui, portanto, uma crítica por dois pontos de vista: (I) ainda é necessário maior autodeterminação, educação e esclarecimento do consumidor antes da implementação de empurrões eticamente responsáveis; e (II) a mineração de dados é condição para essa operação no cenário de big data suscita a necessidade de regulação cooperativa entre Estado e as empresas dotadas de responsabilidade social, sendo o nudge, independente se para bem ou manipulação do consumidor, promotor de massiva mineração de dados pessoais.

Por mais que muitos defendam a utilização de técnicas como o spam e os nudges, seja para informar sobre questões relevantes, seja para induzir decisões corretas, essas práticas dependem fundamentalmente da extração de dados pessoais - por isso, o tema central acaba sendo o desafio de regular a mineração de dados. A possibilidade de proteger direitos do consumidor contra estratégias de empurrões baseadas no comportamento individual é tarefa árdua, pois na era informacional a 
privacidade se situa em completa rendição frente à necessidade de produzir dados comportamentais. A regulação da mineração de dados, dogmaticamente, tem lastro nos Direitos da Personalidade, no Direito do Consumidor e na Proteção de dados. Todavia, no âmbito do consumo, se desfaz ao nível da linguagem profunda da ideologia do consumo, que transforma as necessidades em satisfação, forçando um círculo interminável entre satisfação e insatisfação - um mal-estar que produz, continuamente, dados de comportamento altamente lucrativos para as empresas controladoras. O Direito do Consumidor, ao mesmo tempo em que percebe a vulnerabilidade do ser consumidor, dá sustentabilidade à sua existência, da mesma forma a Lei Geral de Proteção de Dados firma-se em princípios protetivos, mas afirma o mercado de dados.

A regulação da mineração de dados no âmbito do direito do consumidor encontra um profundo impasse: a dogmática jurídica não compreende o papel contraditório e alienante que é o do consumidor e, portanto, não enfrenta o problema da liberdade de escolha e da publicidade com a profundidade necessária - ao nível da linguagem e da ideologia. Frente à inevitabilidade da manipulação de dados na era da big data, sugere-se uma regulação social, tendo como objetivo a auditabilidade social das plataformas que manipulam dados, sendo os usuários capazes de interpretar e analisar os algoritmos que interferem cotidianamente em suas vidas. A regulação da mineração de dados que dá substrato à prática dos nudges exige a conciliação da proteção do consumidor - enquanto evita o assédio de consumo e protege a livre escolha do consumidor - e da proteção dos dados pessoais - enquanto promove práticas de incorporação da privacidade como dever algorítmico.

A pesquisa verificou que isso só será possível, ou avançar nessas pautas só será possível se houver um alinhamento das práticas estatais e não estatais para a formação de um consumidor inteligente, pautado na educação para o consumo, e de processos de participação social via auditabilidade de algoritmos. A aplicação vertical das leis de proteção do consumidor e de proteção de dados não alcançam a realidade de cada vez mais ordens jurídicas baseadas na codificação promovida pelas empresas globais de informática - por isso, é preciso que elas, tendo em vista a responsabilidade social digna de sua dimensão econômica e social, comportem em suas práticas a defesa do consumidor e dos dados pessoais por meio de regulamentos próprios baseados em Direitos Humanos e auditáveis pela sociedade de forma transparente e explicável.

Entretanto, a revolução cultural que sugere Lefebvre depende da superação da oposição entre cotidianidade-festividade, sendo rejeitada a dominação capitalista em prol da apropriação social da vida e da gestão. É preciso uma revolução cultural permanente nas formas de uso das tecnologias da informação, privilegiando o uso democrático e participativo - contrário à realidade monopolista das big techs. A educação do consumidor e uma ética renovada de privacidade podem oportunizar novas formas de vida que percebam como não é necessária a apropriação violenta 
da tecnologia e da publicidade, mas que é possível produzir e consumir de forma sustentável - sem recair em alternativas tecnofóbicas, pelo contrário, na valorização do desenvolvimento humano.

\section{REFERÊNCIAS}

ALVES, Fabrício Germano. Análise da possibilidade de regulação da publicidade comportamental (behavioral advertising) pelo microssistema consumerista.

Revista de Direito, Globalização e Responsabilidade nas Relações de Consumo, v. 2, n. 1, p. 208-223, 2016. Disponível em:

http://www.indexlaw.org/index.php/revistadgrc/article/view/696. Acesso em: 06 abr 2020.

AMBROSINO, Angela; FARALLA, Valeria; NOVARESE, Marco. Nudge, a critical perspective In: MARCIANO, Alain; RAMELLO, Giovanni Battista (eds.).

Encyclopedia of Law and Economics. Cham: Springer, 2017, p. 1-20. Disponível em: https://iris.unito.it/bitstream/2318/1719368/1/nudgefinal24mag17_2.pdf.

Acesso em 22 jul. 2020.

BAUDRILLARD, Jean. Significação da publicidade In: LIMA, Luiz Costa (org). Teoria da cultura de massa. São Paulo: Paz e Terra, 2000, p. 291-299.

BAUMAN, Zygmunt. Vida para o consumo: a transformação das pessoas em mercadoria. 1. ed. Rio de Janeiro: Zahar, 2008.

BIONI, Bruno Ricardo. Inovar pela Lei. GV Executivo, v. 18, n. 4, p. 31-33, 2019. Disponível em:

http://bibliotecadigital.fgv.br/ojs/index.php/gvexecutivo/article/download/79978/7 6432. Acesso em: 06 abr 2020.

BIONI, Bruno Ricardo. Proteção de dados pessoais: a função e os limites do consentimento. Rio de Janeiro: Forense, 2019.

BEZEN, Gabriel Cristina; NETO, Mário Furlaneto. O direito fundamental à educação para o consumo. Revista Jurídica Luso-Brasileira, ano 4, n. 6, p. 535558, 2018. Disponível em:

https://www.cidp.pt/revistas/rjlb/2020/2/2020_02_0535_0558.pdf. Acesso em: 20 jul. 2020.

BRASIL. Lei no 8.078, de 11 de setembro de 1990. Código de Defesa do Consumidor. Disponível em: http://www.planalto.gov.br/ccivil_03/leis/18078.htm. Acesso em: 06 abr 2020. 
BRASIL. Lei no 12.965, de 23 de abril de 2014. Institui o Marco Civil da Internet. Disponível em: http://www.planalto.gov.br/ccivil_03/_ato20112014/2014/lei/112965.htm. Acesso em: 05 abr 2020.

BRASIL. Lei n⿳0 13.709, de 14 de agosto de 2018. Lei Geral de Proteção de Dados Pessoais (LGPD). Disponível em: http://www.planalto.gov.br/ccivil_03/_ato20152018/2018/lei/L13709.htm. Acesso em: 05 abr 2020.

BRUNTON, Finn. Spam: a shadow history of the internet. Cambridge; Londres: The MIT press, 2013.

CAMILO, Cássio Oliveira; SILVA, João Carlos da. Mineração de Dados:

Conceitos, Tarefas, Métodos e Ferramentas. Relatório Técnico - RT-INF_001-09. 2009. Disponível em: https://rozero.webcindario.com/disciplinas/fbmg/dm/RTINF_001-09.pdf. Acesso em: 01 abr 2020.

CAMURÇA, Lia Carolina Vasconcelos. Sociedade de vigilância, direito à privacidade e proteção de dados pessoais: uma análise sobre a influência de técnicas de publicidade comportamental na internet no consumidor-usuário. 2020. Dissertação (mestrado em Direito) - Universidade Federal do Ceará, Fortaleza, 2020. Disponível em:

http://repositorio.ufc.br/bitstream/riufc/51045/1/2020_dis_lcvcamur\%c3\%a7a.pdf. Acesso em: 20 jul. 2020.

CASTELLANO, Andrea; SARDI, María Celeste Chaz. Protección del Consumidor: Regulación de la Publicidad y el Uso de Nudges. The Latin American and Iberian Journal of Law and Economics, v. 2, n. 1, p. 135-150, 2016. Disponível em: https://ri.conicet.gov.ar/bitstream/handle/11336/52088/CONICET_Digital_Nro.51b 6a80f-7ae5-424c-964c-80b052148c6e_A.pdf?sequence=2\&isAllowed=y. Acesso em: 06 abr 2020.

CATALAN, Marcos; PITOL, Yasmine Uequed. Primeiras linhas acerca do tratamento jurídico do assédio de consumo no Brasil. Revista luso-brasileira de Direito do Consumo, v. 7, n. 25, p. 137-160, 2017. Disponível em: https://www.academia.edu/30769080/Primeiras_linhas_acerca_do_tratamento_jur $\%$ C3\%Addico do ass\%C3\%A9dio de consumo no Brasil. Acesso em: 20 jul. 2020 .

CEROY, Frederico Meinberg. Os conceitos de provedores no Marco Civil da Internet. Direito e TI, Porto Alegre, n. 9, 2014. Disponível em: http://direitoeti.com.br/site/wp-content/uploads/2015/09/CEROY-Frederico- 
Meinberg-O-Conceito-de-Provedores-no-Marco-Civil-da-Internet.pdf. Acesso em: 20 jul. 2020.

CIOATTO, Roberta Marina; PINHEIRO, Adriana de Alencar Gomes. Nudges como política pública para aumentar o escasso número de doadores de órgãos para transplante. Revista Brasileira de Políticas Públicas, v. 8, n. 2, p. 368-384, 2018. Disponível em:

https://www.publicacoesacademicas.uniceub.br/RBPP/article/view/5271. Acesso em: 05 abr 2020.

COLOMBO, Cristiano; FACCHINI NETO, Eugênio. Mineração de dados e análise preditiva: reflexões sobre possíveis violações ao direito de privacidade na sociedade da informação e critérios para sua adequada implementação à luz do ordenamento brasileiro. Revista de Direito, Governança e Novas Tecnologias, v. 3, n. 2, p. 59-80, 2017. Disponível em: https://www.indexlaw.org/index.php/revistadgnt/article/view/2345/pdf. Acesso em: 03 abr 2020.

COURTLAND, Rachel. Bias detectives: the researchers striving to make algorithms fair: As machine learning infiltrates society, scientists are trying to help ward off injustice. Nature, n. 558, p. 357-361, 2018. Disponível em: https://www.nature.com/magazine-assets/d41586-018-05469-3/d41586-018-054693.pdf. Acesso em: 06 abr 2020.

CRAIN, Matthew. The limits of transparency: data brokers and commodification. New Media and Society, v. 20, n. 1, p. 88-104, 2018.

CUKIER, Kenneth; MAYER-SCHOENBERGER, Viktor. The rise of big data: how it's changing the way we think about the world. Foreign Affairs, [s.l.], v. 92, 2013. DOI: https://doi.org/10.1515/9781400865307-003.

DAURA, Samir Alves. Behavioral economics e o direito do consumidor. Revista Brasileira de Políticas Públicas, Brasília, v. 8, n. 2, p. 567-598, 2018. DOI: 10.5102/rbpp.v8i2.5330.

DONEDA, Danilo. A proteção de dados pessoais nas relações de consumo: para além da informação creditícia. Escola Nacional de Defesa do Consumidor. Caderno de investigações científicas, vol. 2. Brasília: SDE/DPDC, 2010. Disponível em: https://www.justica.gov.br/seus-direitos/consumidor/Anexos/manual-deprotecao-de-dados-pessoais.pdf. Acesso em: 01 abr 2020. 
DONEDA, Danilo. Da privacidade à proteção de dados pessoais. São Paulo: Revista dos Tribunais, 2006.

DOWNBOR, Ladislau. Consumo inteligente. In: MENDES JR., Ricardo; DOWNBOR, Ladislau; SILVA, Hélio (org). Desafios do consumo. Petrópolis: Editora Vozes, 2007. p. 11-29.

ESTRADA, Manuel Martín Pino. O Comércio De Dados Pessoais Dos Trabalhadores Pelas Empresas De Tecnologia E Pelos Governos Através Da Invasão Da Privacidade E Da Intimidade. In: EINLOFT, Denis; TOSS, Luciane; SEVERO, Valdete Souto. Direito do Trabalho e Pensamento Crítico. Porto Alegre: Hs Editora, 2016, p. 79-95.

FEITOSA, Gustavo Raposo Pereira; CRUZ, Antonia Camily Gomes. Nudges fiscais: a economia comportamental e o aprimoramento da cobrança da dívida ativa. Pensar-Revista de Ciências Jurídicas, v. 24, n. 4, 2019. Disponível em: https://periodicos.unifor.br/rpen/article/view/10258. Acesso em: 05 abr 2020.

FERRARA, Emilio. The history of Digital Spam. Communication of the ACM, v. 62, n. 6, p. 82-91, 2019. Disponível em: https://dl.acm.org/doi/pdf/10.1145/3299768. Acesso em: 05 abr 2020.

FINKELSTEIN, Maria Eugênia. Aspectos jurídicas do comércio eletrônico. Porto Alegre: Síntese, 2004.

FORNASIER, Mateus de Oliveira; FERREIRA, Luciano Vaz. A regulação das empresas transnacionais entre as ordens jurídicas estatais e não-estatais. Revista de Direito Internacional, v. 12, n. 1, 2015. Disponível em:

https://search.proquest.com/openview/6954c2d71dbca6be57d8cae82503ddd5/1?pq -origsite $=$ gscholar\&cbl=2031896. Acesso em: 01/12/2019.

FUCHS, Christian. Critique of the political economy of web 2.0 surveillance. In: FUCHS, C. (et al). Internet and surveillance: the challenges of web 2.0 and social media. New York: Routledge, p. 31-70, 2011.

GAJITOS, Marisun. Hacia el consumo inteligente. Comunicar, Huelva - Espanha, n. 47, p. 43-46, 2006. Disponível em:

https://www.redalyc.org/pdf/158/15802707.pdf. Acesso em: 20 jul 2020.

GRODERS, Elisandra Duarte. Preferências do consumidor por produtos orgânicos: nudges e o uso de normas descritivas. Dissertação (mestrado em Economia) - Faculdade de Economia da Universidade Federal do Rio Grande do 
Sul. 2017. Disponível em: https://www.lume.ufrgs.br/handle/10183/158149. Acesso em: 05 abr 2020.

KANTARDZIC, Mehmed. Data Mining: concepts, models, methods and algorithms. 3 ed. New York: IEEE Press; Wiley, 2020.

KEMPER, Jakko; KOLKMAN, Daan. Transparent to whom? No algorithmic accountability without a critical audience. Information, Communication \& Society, v. 22, n. 14, p. 2081-2096, 2019. Disponível em: https://www.tandfonline.com/doi/pdf/10.1080/1369118X.2018.1477967?needAcces s=true. Acesso em: 05 abr 2020.

KREBS, Brian. Spam Nation: The inside story of organized cybercrime: from global epidemic to you front door. Naperville: Sourcebooks, 2014.

LEFEBVRE, Henri. A vida cotidiana no mundo moderno. Tradução de Alcides João de Barro. São Paulo: Editora Ática, 1991.

LEMBCKE, Tim-Benjamin; ENGELBRECHT, Nils; BRENDEL, Alfred Benedikt. To nudge or not to nudge: ethical considerations of digital nudgind based on its behavioral economics roots. In: Proceedings of the 27th European Conference on Information Systems (ECIS), Estocolmo, 2019, p. 1-17. Disponível em: https://aisel.aisnet.org/cgi/viewcontent.cgi?article=1094\&context=ecis2019_rp. Acesso em: 20 jul. 2020.

LEMOS; Ronaldo; DONEDA, Danilo; SOUZA, Carlos Affonso Pereira de; ROSSINI, Carolina Almeida A.. Estudo sobre a regulamentação jurídica do spam no Brasil. Rio de Janeiro: FGV, 2007. Disponível em: https://bibliotecadigital.fgv.br/dspace/bitstream/handle/10438/2684/Estudo_SPAM _CTS.pdf?sequence=1\&isAllowed=y. Acesso em: 05 abr 2020.

MACHADO, Fernando Inglez; RUARO, Regina Linden. Publicidade Comportamental, Proteção De Dados Pessoais E O Direito Do Consumidor. Conpedi Law Review, v. 3, n. 2, p. 421-440, 2017. Disponível em: http://repositorio.pucrs.br/dspace/bitstream/10923/11550/2/PUBLICIDADE_COM PORTAMENTAL_PROTECAO_DE_DADOS_PESSOAIS_E_O_DIREITO_DO_CO NSUMIDOR.pdf. Acesso em: 06 abr 2020.

MAGRANI, Eduardo. A ética das "coisas": da ética do discurso e racionalidade comunicativa ao novo materialismo de sistemas sociotécnicos. 2 ed. Porto Alegre: Arquipélago, 2019. Disponível em: http://eduardomagrani.com/wp- 
content/uploads/2019/07/Entre-dados-e-robo\%CC\%82s-Pallotti-13062019.pdf. Acesso em 20 jul. 2020.

MATOS, Tiago Farina. Comércio de dados pessoais, privacidade e internet.

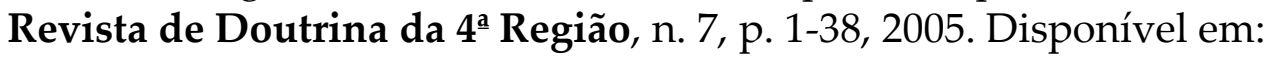
https://pdfs.semanticscholar.org/69e9/126d0183867f182db2ecb58cc3226260a942.pd f. Acesso em: 05 abr 2020.

MARQUES, Claudia Lima. Conciliação em matéria de superendividamento dos consumidores: principais resultados de um estudo empírico de 5 anos em Porto Alegre. Estudos de Direito do Consumidor, v. 11, p. 13-43, 2016. Disponível em: https://www.enfam.jus.br/wp-content/uploads/2020/05/11-Artigo-CLMCoimbraconciliacao6fimenv-4.1.pdf. Acesso em: 20 jul. 2020.

MARQUES, Claudia Lima. Consumo como igualdade e inclusão social: a necesssidade de uma lei espacial para preveninr e tratar o superendividamento dos consumidores pessoas físicas. Revista Jurídica da Presidência, v. 13, n. 101, p. 405-424, 2012. Disponível em:

https://revistajuridica.presidencia.gov.br/index.php/saj]/article/download/119/111. Acesso em: 21 jul. 2020.

MENDES, Laura Schertel; DONEDA, Danilo. Marco jurídico para a cidadania digital: uma análise do Projeto de Lei 5.267/2016. Revista de Direito Civil Contemporâneo - RDCC (Journal of Contemporary Private Law), v. 9, p. 35-48, 2017.

MENDES, Laura Schertel. O diálogo entre o Marco Civil da Internet e o Código de Defesa do Consumidor. Revista de Direito do Consumidor, São Paulo, v. 106, ano 25, p. 37-69, 2016.

MIRAGEM, Bruno. A lei geral de proteção de dados e o Direito do Consumidor. Revista dos Tribunais, v. 1009, 2019.

PINHEIRO, Patricia Peck. Proteção de dados pessoais: comentários à Lei n. 13.709/2018 (LGPD). 2 ed. São Paulo: Saraiva, 2020.

SERRANO, Pablo Jiménez; MARTINEZ, Regina Célia. A educação para o consumo consciente: um componente básico para a concretização da eficácia do direito do consumidor brasileiro. Revista Jurídica - Unicuritiba, Curitiba, v. 2, n. 59, p. 311-342, 2020. DOI: http://dx.doi.org/10.21902/revistajur.2316753X.v2i59.4093 
SILVEIRA, Sebastião Sérgio; PERES, Edilon Volpi. Cidadania digital: necessidade de ponderação entre os valores constitucionais relativos a proteção ao consumidor e aqueles contemplados na lei do marco civil da internet. Revista Faculdade de Direito UFG, v. 43, p. 01-16, 2019. DOI: https://doi.org/10.5216/rfd.v43.57192

SOUZA, Luciana Cristina; RAMOS, Karen Tobias França; PERDIGÃO, Sônia Carolina Romão Viana. Análise crítica da orientação de cidadãos como método para otimizar decisões públicas por meio da técnica nudge. Revista Brasileira de Políticas Públicas, v. 8, n. 2, p. 234-250, 2018. Disponível em: https://www.arqcom.uniceub.br/RBPP/article/view/5314. Acesso em: 05 abr 2020.

SUNSTEIN, Cass R.; REISCH, Lucia A. Trusting nudges: toward a Bill of rights for nudging. Londres; Nova Iorque: Routledge, 2019.

SUNSTEIN, Cass R. Misconceptions about nudges. 2017a. Disponível em: https://papers.ssrn.com/sol3/papers.cfm?abstract id=3033101. Acesso em: 21 jul. 2020.

SUNSTEIN, Cass R. Nudging: um guia (muito) resumido. REI - Revista Estudos Institucionais, Rio de Janeiro, v. 3, n. 2, p. 1023-1044, 2017b. Disponível em: https://estudosinstitucionais.com/REI/article/view/223. Acesso em: 05 abr 2020.

SUNSTEIN, Cass R. Nudging and choice architecture: ethical considerations. Yale journal on regulation. 2015. Disponível em: https://papers.ssrn.com/sol3/papers.cfm?abstract_id=2551264. Acesso em: 20 jul. 2020.

SUNSTEIN, Cass R. Why nudge?: the politics of libertarian paternalism. New Haven: Yale University Press, 2014.

TATEOKI, Victor Augusto. A proteção de dados pessoais e a publicidade comportamental. Revista Juris UniToledo, v. 2, n. 01, p. 62-75, 2017. Disponível em: http://ojs.toledo.br/index.php/direito/article/view/113/89. Acesso em: $06 \mathrm{abr}$ 2020.

TEIXEIRA, Tarcisio. Curso de Direito e processo eletrônico: doutrina, jurisprudência e prática. 3 ed. São Paulo: Saraiva: 2015.

TIUJO, Mitsuo. El derecho fundamental a la educación formal para el consumo como medio de concreción del derecho a la libertad de elección del consumidor e igualdad en las contrataciones e implementación del derecho coletivo y social de 
protección al medio ambiente. Revista Pedagogía Universitaria y Didáctica Del Derecho, v. 5, n. 1, p. 35-58. DOI: 10.5354/0719-5885.2018.50406.

VEDDER, Anton; NAUDTS, Laurens. Accountability for the use of algorithms in a big data environment. International Review of Law, Computers \& Technology, v. 31, n. 2, p. 206-224, 2017. Disponível em:

https://www.tandfonline.com/doi/pdf/10.1080/13600869.2017.1298547?needAccess $=$ true. 06 abr 2020.

VERBICARO, Dennis; CRUZ, Raíza. O dano existencial na sociedade de consumo. Revista Jurídica da FA7, Fortaleza, v. 15, n. 1, p. 47-62, 2018. Disponível em: https://periodicos.uni7.edu.br/index.php/revistajuridica/article/view/504/465. Acesso em: 20 jul. 2020.

VERBICARO, Dennis; RODRIGUES, Lays; ATAÍDE, Camille. Desvendando a vulnerabilidade comportamental do consumidor: uma análise jurídico-psicológica do assédio de consumo. Revista de Direito do Consumidor, São Paulo, v. 119, ano 27, p. 349-384, set-out. 2018.

VERBICARO. Loaiane da Ponte Souza Prado; VERBICARO, Dennis. A indústria cultural e o caráter fictício da individualidade na definição de consumidorcomunidade global. Revista Jurídica Cesumar- Mestrado, v. 17, b. 1, p. 107-131, 2017. DOI: http://dx.doi.org/10.17765/2176-9184.2017v17n1p107-131.

VIEIRA, Miguel Said; EVANGELISTA, Rafael. A máquina de exploração mercantil da privacidade e suas conexões sociais (The Mercantile PrivacyExploiting Machine and Its Social Connections). In: 3rd International LAVITS Symposium, Rio de Janeiro, 2015. Disponível em:

https://papers.ssrn.com/sol3/papers.cfm?abstract_id=2608251. Acesso em: 06 abr 2020.

VIEIRA, Adriana Carvalho Pinto; KACHUBA, Daiane; LOCATELLI, Liliana. Sociedade de consumo, superenvidamento e economia comportamental. Revista Contribuciones a las Ciencias Sociales, Chapingo, v. 1, p. 1-20, 2020. Disponível em: https://www.eumed.net/rev/cccss/2020/03/sociedade-consumo.html. Acesso em: 20 jul. 2020.

VONBERGEN, Clarence; KERNEK, Courtney; BRESSLER, Martin S.; SILVER, Lawrence. Cueing the Customer Using Nudges and Negative Option Marketing. Atlantic Marketing Journal, v. 5, n.2, p. 151-168, 2016. Disponível em: https://digitalcommons.kennesaw.edu/cgi/viewcontent.cgi?article=1188\&context= amj. Acesso em: 06 abr 2020. 
